\title{
Quantifying GRACE data contamination effects on hydrological analysis in the Murray-Darling Basin, southeast Australia
}

\section{N. J. BROWN ${ }^{1 *}$ AND P. TREGONING ${ }^{2}$}

'Geoscience Australia, GPO Box 378 Canberra, ACT 2601, Australia.

${ }^{2}$ Research School of Earth Sciences, Australian National University, ACT 0200, Australia.

\begin{abstract}
This paper investigates and quantifies the near-field and far-field contamination effects from Groupe de Recherche en Géodesie Spatiale GRACE products to assess whether or not they influence the accuracy with which hydrological signals in the Murray-Darling Basin, southeast Australia can be estimated. Far-field contamination was assessed by simulating some of the world's largest geophysical processes which generate major gravitational signals (e.g. melting of the Greenland icesheet, hydrology in the Amazon Basin) and measuring the proportion of the simulated signal detected in the Murray-Darling Basin. Near-field contamination from the Australian continent (excluding the Murray-Darling Basin) was also assessed. The sum of the near-field and far-field effects revealed a maximum of $\sim 10 \mathrm{~mm}$ (equivalent water height) of spurious signal within the MurrayDarling Basin. This equates to only one quarter of the formal uncertainty of the basin-scale estimates of changes in total water storage. Thus, GRACE products can be used to monitor broad-scale hydrological trends and variability in the Murray-Darling Basin without the need to account for contamination from external geophysical sources.
\end{abstract}

KEY WORDS: GRACE, hydrology, modelling, Murray-Darling Basin, satellite geodesy.

\section{INTRODUCTION}

The Gravity Recovery and Climate Experiment (GRACE) Project is jointly managed by National Aeronautics and Space Administration (NASA) and Deutsches Zentrum für Luft-und Raumfahrt (DLR) (Tapley et al. 2004). The products derived from GRACE satellite data provide accurate models for both the static and time variable components of the Earth's gravity field such as the oceans (Wahr et al. 2002), ice sheets (Ramillien et al. 2006) and land hydrology (Ramillien et al. 2005; Schmidt et al. 2006; Leblanc et al. 2009).

The Murray-Darling Basin is the source of $\sim 85 \%$ of Australia's irrigation and supports an agriculture industry valued at over $\$ 9$ billion per annum (DEWHA 2009). Leblanc et al. (2009) showed a high correlation in the Murray-Darling Basin between groundwater variations observed by borehole measurements and total water storage from GRACE. This demonstrates the ability of GRACE products to track groundwater variations, although it is difficult to quantify the uncertainty of the estimates because of the sparse ground-based groundwater and gravity measurements.
Fundamental to any measurement is a strong understanding of the associated uncertainty. Global GRACE spherical-harmonic fields are truncated at some pre-defined degree in the estimation process. Consequently, the finite number of spherical-harmonic coefficients causes leakage or ripples in the global gravity fields (Swenson \& Wahr 2002; Seo \& Wilson 2005). That is, the inability of the chosen spherical-harmonic models to perfectly model a region causes geophysical signals to propagate through the spherical harmonics and contaminate other regions of interest. For example, the Groupe de Recherche en Géodesie Spatiale products used in this analysis have global averaged formal uncertainties of $\sim 40 \mathrm{~mm}$ of equivalent water height for each solution (Llubes et al. 2007).

Velicogna \& Wahr (2006) modelled and removed the contamination from hydrological signals from their estimates of Antarctic mass-balance change using the GLDAS hydrological model (Rodell et al. 2004). Other authors (Ramillien et al. 2006) have adopted similar techniques. However, the accuracy of this process is dependent on the accuracy of the hydrology model to represent the actual signals. The magnitude of the correction applied is generally not indicated, although

*Corresponding author: nicholas.brown@ga.gov.au

ISSN 0812-0099 print/ISSN 1440-0952 online ( $) 2010$ Commonwealth of Australia (Geoscience Australia) DOI: $10.1080 / 08120091003619241$ 
Velicogna \& Wahr (2006) claimed that $24 \%$ of the $+51 \pm 14 \mathrm{~km}^{3} /$ a ice volume trend in Antarctica was caused by hydrology leakage.

This paper quantifies the magnitude of spurious signals that appear in estimates of total water storage in the Murray-Darling Basin from not only the near-field, but also from some of the largest geophysical processes throughout the world. A combination of simulations and analysis of real data was used to extract information on the amount of contamination that is likely to occur in estimates of hydrological processes.

\section{GRACE PRODUCTS}

The Earth's global gravity field is often described in terms of the shape of the geoid, $N$ (Wahr et al. 1998).

$$
N(\theta, \phi)=\sum_{l=0}^{\infty} \sum_{m=0}^{l} \tilde{P}_{l m}(\cos \theta)\left(U_{l m} \cos (m \phi)+V_{l m} \sin (m \phi)\right)
$$

For some colatitude, $\theta$, and east longitude, $\phi$, it is usual to expand the geoid shape as a sum of spherical harmonics (Chao \& Gross 1987) where $l$ and $m$ are the harmonic degree and order, $U_{l m}$ and $V_{l m}$ are the geoid coefficients, and $\tilde{P}_{l m}$ are the normalised associated Legendre functions.

The GRACE Project analysis centres, the Center for Space Research and GeoForschungsZentrum Potsdam, evaluate the spherical-harmonic products up to degree 60 and 120 respectively (GRACE 2007). In order to recover geophysical signals the project introduced filtering techniques to reduce the contribution of the noisiest short-wavelength component (Swenson \& Wahr 2002, 2006). In contrast, the Groupe de Recherche en Géodesie Spatiale (GRGS) from Centre National d'Etudes Spatiales has developed its own spherical-harmonic products to degree 50 (Lemoine et al. 2007). The GRGS applies an empirical constraint on the deviation of the estimated coefficients from a mean gravity field and limits the spherical-harmonic fields to degree 50 , since above this degree the GRACE observations do not contain sufficient power to vary the estimated coefficients away from the mean gravity field. The applied empirical constraints reduce the noise in the spherical-harmonic fields, which do not require subsequent filtering in order to extract and interpret geophysical variations of the Earth's gravity field (Lemoine et al. 2007).

Below we use the GRGS monthly solutions, created by accumulating three consecutive 10 day matrices in which the central 10 day matrix was weighted doubly (Lemoine et al. 2007). The atmospheric mass, ocean tide and ocean mass signals were modelled using data from the European Centre for Medium-range Weather Forecasts, the Finite Element Solution 2004 (FES2004) (Lyard et al. 2006) and the MOG2D-G barotropic (Carrère \& Lyard 2003) models. Any remaining signals are therefore assumed to correspond to gravitational variability caused by Earth processes such as continental hydrology, non-tidal oceanic variations, melting of ice sheets or glacial isostatic adjustment.

\section{GEOPHYSICAL SIGNALS}

Geophysical signals from Australia and 18 of the world's major geophysical processes (Figure 1) were extracted from the GRGS solutions over the period 2002.6 to 2008.1. Using least squares, periodic and/or linear trends were estimated for each source and were subsequently used to generate synthetic spherical-harmonic fields over the same time period. We generated the simulated fields for each geophysical signal separately as well as the combination of all signals. Importantly, no signal was modelled in the Murray-Darling Basin itself. Thus, any signal detected in the Murray-Darling Basin must be contamination from the simulated sources.

\section{Extracting geophysical signals}

We generated kernels to describe geographical regions, with boundaries derived from Oki \& Sud (1998). Following, for example, Ramillien et al. (2006), we assigned a value of 1 inside each simulation source and 0 outside, then generated a spherical-harmonic representation (to degree 50) of the region (Figure 2). Next, these geographical masks were used to extract geophysical signals from the GRACE product in units of equivalent water height (EWH) (Ramillien et al. 2006):

$$
\delta \Psi(t)=4 \pi R^{2} \sum_{l=2}^{l \max } \sum_{m=0}^{l}\left(\left(A_{l m} \delta C_{l m}(t)\right)+\left(B_{l m} \delta S_{l m}(t)\right)\right)
$$

where $\delta \Psi(t)$ is the integrated variation in gravity (expressed in terms of volume of water) at time $t ; A_{l m}$, $B_{l m}$ are normalised harmonic coefficients of the kernel; and $\delta C_{l m}(t), \delta S_{l m}(t)$ are the surface mass density anomalies (Ramillien et al. 2006):

$$
\left(\begin{array}{c}
\delta C_{l m}(t) \\
\delta S_{l m}(t)
\end{array}\right)=\left[\frac{4 \pi G \rho_{w} R}{(2 l+1) \bar{\gamma}}\left(1+k_{l}^{\prime}\right)\right]^{-1} \times\left(\begin{array}{c}
\delta U_{l m}(t) \\
\delta V_{l m}(t)
\end{array}\right)
$$

where geoid anomalies $\delta U_{l m}, \delta V_{l m}$ were calculated by subtracting the mean value from the time period 2002.6 to $2008.1, G$ is the gravitational constant $(6.673 \times$ $\left.10^{-11} \mathrm{~m}^{3} \mathrm{~kg}^{-1} \mathrm{~s}^{-2}\right), \rho_{w}$ is the mean density of freshwater $\left(1000 \mathrm{~kg} \mathrm{~m}^{-3}\right), R$ is the mean radius of the Earth $(6371 \mathrm{~km}), \bar{\gamma}$ is the mean gravity acceleration $\left(9.807 \mathrm{~m} \mathrm{~s}^{-2}\right)$ and $k_{l}^{\prime}$ is the elastic Love number of degree $l$ (Wahr et al. 1998).

The corresponding variation in units of equivalent water height at time, $t$, was estimated by dividing the variation in volume of water, $\delta \Psi(t)$, by the surface area of the kernel.

\section{Simulating geophysical processes}

We used the time series of each geophysical source to estimate periodic and/or linear trend parameters of 


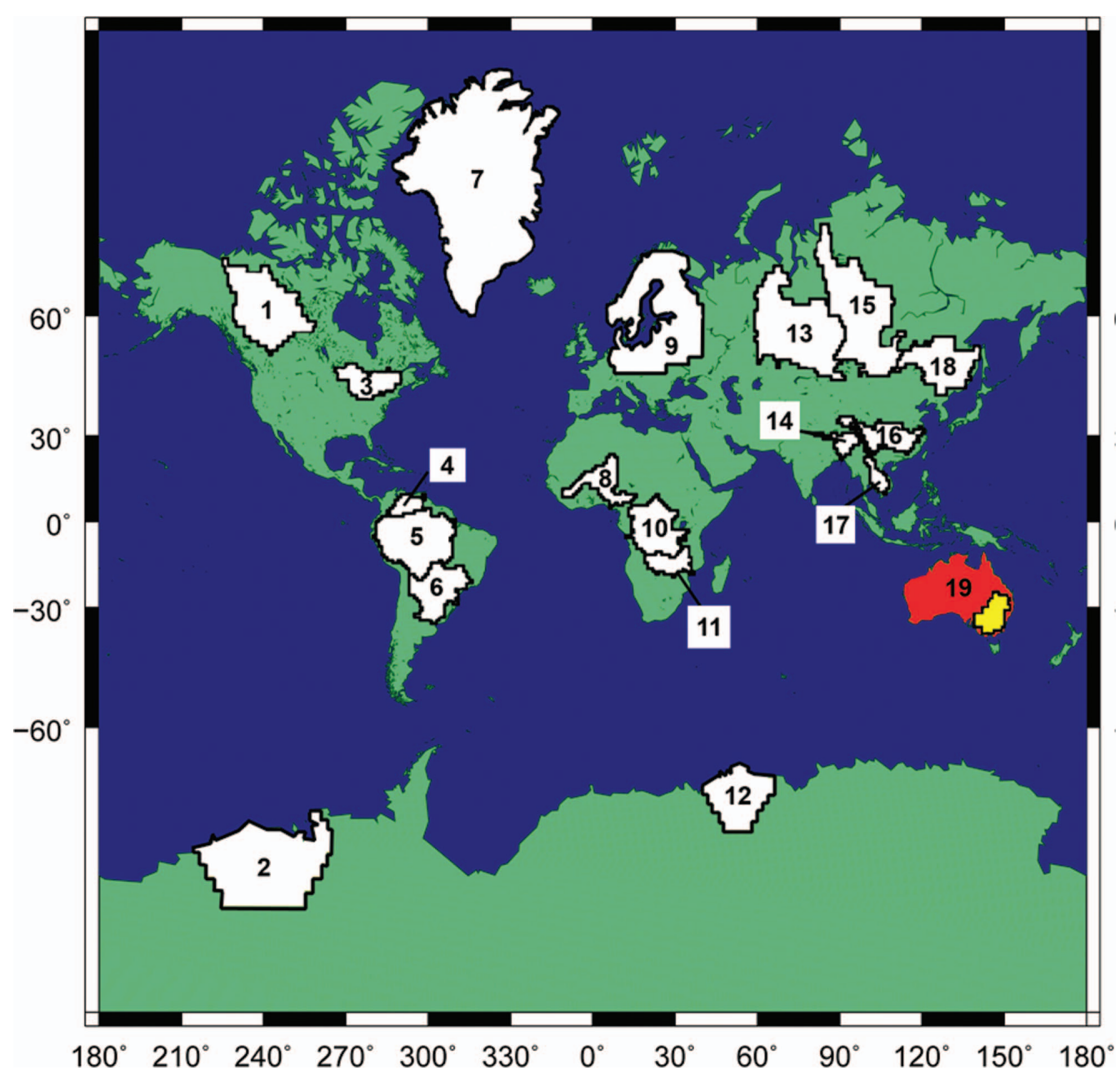

Figure 1 Near-field (19, Australia) and far-field contamination sources from 18 of the major sources of gravitational variability in the world: 1, Mackenzie Basin; 2, West Antarctica; 3, St Lawrence Basin; 4, Orinoco Basin; 5, Amazon Basin; 6, Parana Basin; 7, Greenland; 8, Niger Basin; 9, Fennoscandia; 10, Congo Basin; 11, Zambezi Basin; 12, East Antarctica; 13, Ob Basin; 14, Brahmaputra Basin; 15, Yenisey Basin; 16, Yangtze Basin; 17, Mekong Basin; 18, Amur Basin.

a function defining the simulated $\mathrm{EWH}\left(\mathrm{EWH}_{\mathrm{SIM}}\right)$ at time $t$ :

$$
\mathrm{EWH}_{\mathrm{SIM}}(t)=a(\cos (2 \pi x))+b(\sin (2 \pi x))+c x+d
$$

where $a, b, c$ and $d$ are least-squares-derived coefficients and $x$ is the epoch in decimal years. Examples of the observed and modelled signals are shown in Figure 3. While it is clear that this simple functional model does not represent all of the observed signals, it captures the first-order effects and is sufficient to model the magnitude of the signals.
Next, the functions were used to generate synthetic gravity anomaly fields of $0.25^{\circ}$ resolution from 2002.6 to 2008.1 for each of the geophysical processes. Grid cells inside the source kernels were assigned the values calculated using equation 4 and those outside the kernel were assigned values of zero. Each global grid was then converted to a spherical-harmonic representation yielding synthetic coefficient anomalies $\delta C_{l m}, \delta S_{l m}$ for each epoch.

The amount of contamination from each source that propagates into the Murray-Darling Basin was then evaluated using equation 2 , where $A_{l m}, B_{l m}$ are the normalised harmonic coefficients for the kernel of the Murray-Darling Basin. 


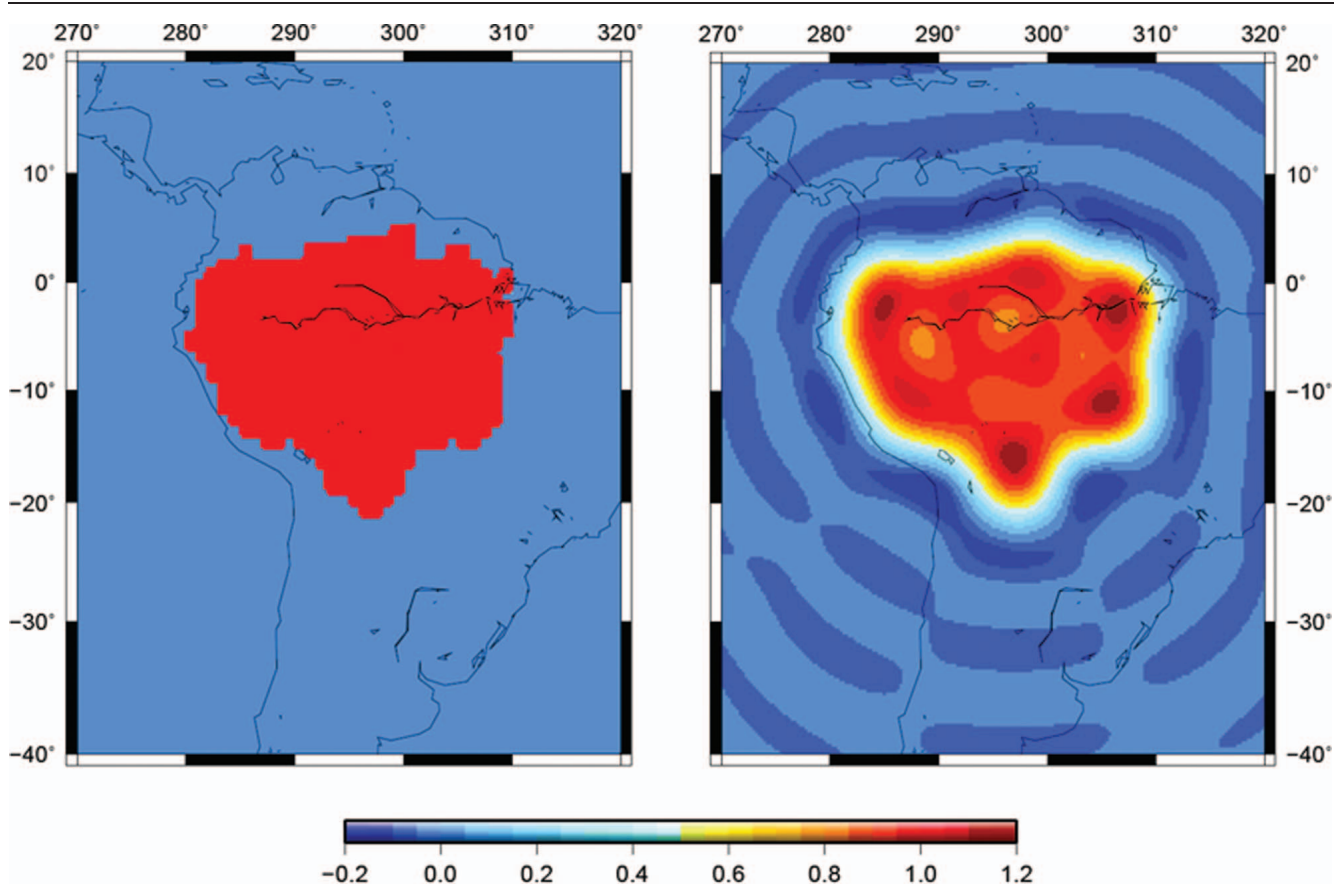

Figure 2 Gridded kernel (left) and spherical-harmonic representation (right) for the Amazon Basin.
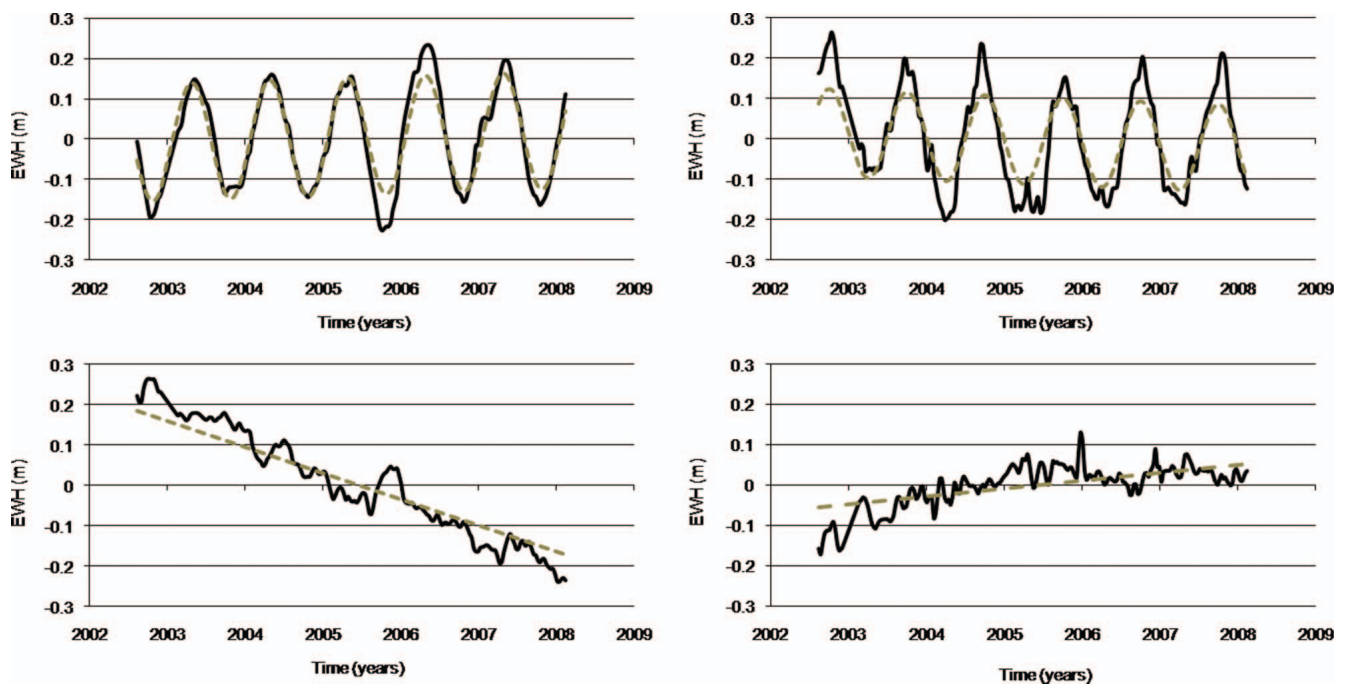

Figure 3 GRGS time series (black solid line) and simulated time series (grey dashed line) from 2002.6 to 2008.1 of (clockwise from top left) Amazon Basin, Mekong Basin, East Antarctica and West Antarctica.

\section{QUANTIFYING CONTAMINATION}

The contamination from a simulation source, $\% C_{\text {SIM }}$, can be represented as a percentage of the source signal (Table 1):

$$
\% C_{\mathrm{SIM}}=\frac{\mathrm{EWH}_{\mathrm{SIM}(\mathrm{MDB})}(t)}{\mathrm{EWH}_{\mathrm{SIM}(\mathrm{SOURCE})}(t)} \times 100
$$

where $\mathrm{EWH}_{\mathrm{SIM}(\mathrm{SOURCE})}(t)$ is the simulated $\mathrm{EWH}$ value in the source, and $\mathrm{EWH}_{\mathrm{SIM}(\mathrm{MDB})}(t)$ is the component of 
the source signal that appears within the Murray-Darling Basin at time $t$. Approximately $12 \%$ of the Australian gravity signal contaminates the Murray-Darling Basin and the largest far-field contamination originates from the Amazon Basin, with $1.37 \%$.

We can then use this percentage to convert the magnitudes of actual observed geophysical signals at

Table 1 Simulated annual variations and estimated contamination effects in the Murray-Darling Basin.

\begin{tabular}{rlcr}
\hline ID & Source & $\begin{array}{c}\text { Simulated annual } \\
\text { variation in } \\
\text { EWH }(\mathrm{mm})\end{array}$ & $\% C_{\text {SIM }}$ \\
\hline 19 & Australia & \pm 30 & \\
5 & Amazon & \pm 150 & 11.71 \\
16 & Yangtze & \pm 33 & 1.37 \\
9 & Fennoscandia & +5 & 0.91 \\
8 & Niger & \pm 55 & 0.88 \\
18 & Amur & \pm 20 & 0.78 \\
7 & Greenland & -31 & 0.63 \\
17 & Mekong & \pm 100 & 0.60 \\
2 & West Antarctica & -100 & 0.58 \\
3 & St. Lawrence & \pm 27 & 0.44 \\
15 & Yenisey & \pm 21 & 0.37 \\
6 & Parana & \pm 48 & 0.36 \\
12 & East Antarctica & +27 & 0.35 \\
14 & Brahmaputra & \pm 125 & 0.34 \\
4 & Orinoco & \pm 150 & 0.32 \\
10 & Congo & \pm 40 & 0.30 \\
1 & Mackenzie & \pm 22 & 0.29 \\
13 & Ob & \pm 30 & 0.18 \\
11 & Zambezi & \pm 110 & 0.14 \\
\hline
\end{tabular}

each epoch into the magnitude of spurious signal that appears in the Murray-Darling Basin estimates:

$$
C_{\text {SOURCE IN MDB }}(t)=\frac{\% C_{\mathrm{SIM}}}{100} \times \mathrm{EWH}_{\mathrm{GRGS}(\text { SOURCE) }}(t)
$$

where $\mathrm{EWH}_{\mathrm{GRGS} \text { (SOURCE) }}(t)$ is the EWH value of the source calculated from GRGS products at time $t$.

Finally, the total contamination from Australia and the 18 far-field sources were summed

$$
C_{\text {TOTAL }}(t)=\sum_{1}^{19} C_{\text {SOURCE IN MDB }}(t)
$$

yielding a time series of contamination in the MurrayDarling Basin (Figure 4).

The contamination effect is not cumulative since the geophysical signal and contamination are not always in phase, with the latter being dependent on the location of the source relative to the MurrayDarling Basin. This is evidence of the ripple effect (Seo \& Wilson 2005).

The maximum amount of combined contamination detected was $\sim 10 \mathrm{~mm}$ (Figure 4 ). The hydrological signals detected in the Murray-Darling Basin are in the order of $50-100 \mathrm{~mm}$ (Figure 5), with formal uncertainties of each estimate of $\sim 40 \mathrm{~mm}$ (Llubes et al. 2007). Although the combined contamination does not represent all contamination sources throughout the world, it does account for the majority of contamination and we therefore believe the analysis is sufficient to claim that contamination effects are insignificant and can be ignored when assessing hydrological trends in the Murray-Darling Basin.

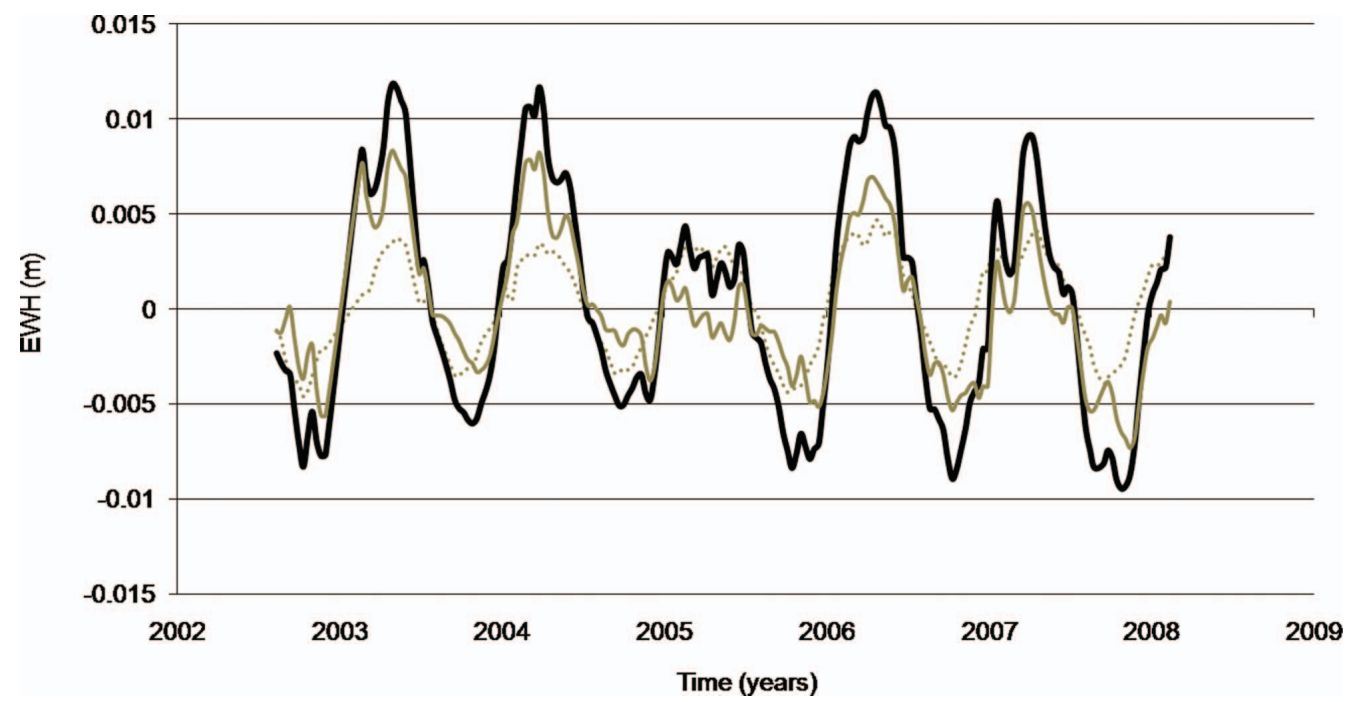

Figure 4 Near-field (grey line), far-field (dotted grey line) and combined contamination (black line) in the Murray-Darling Basin. 


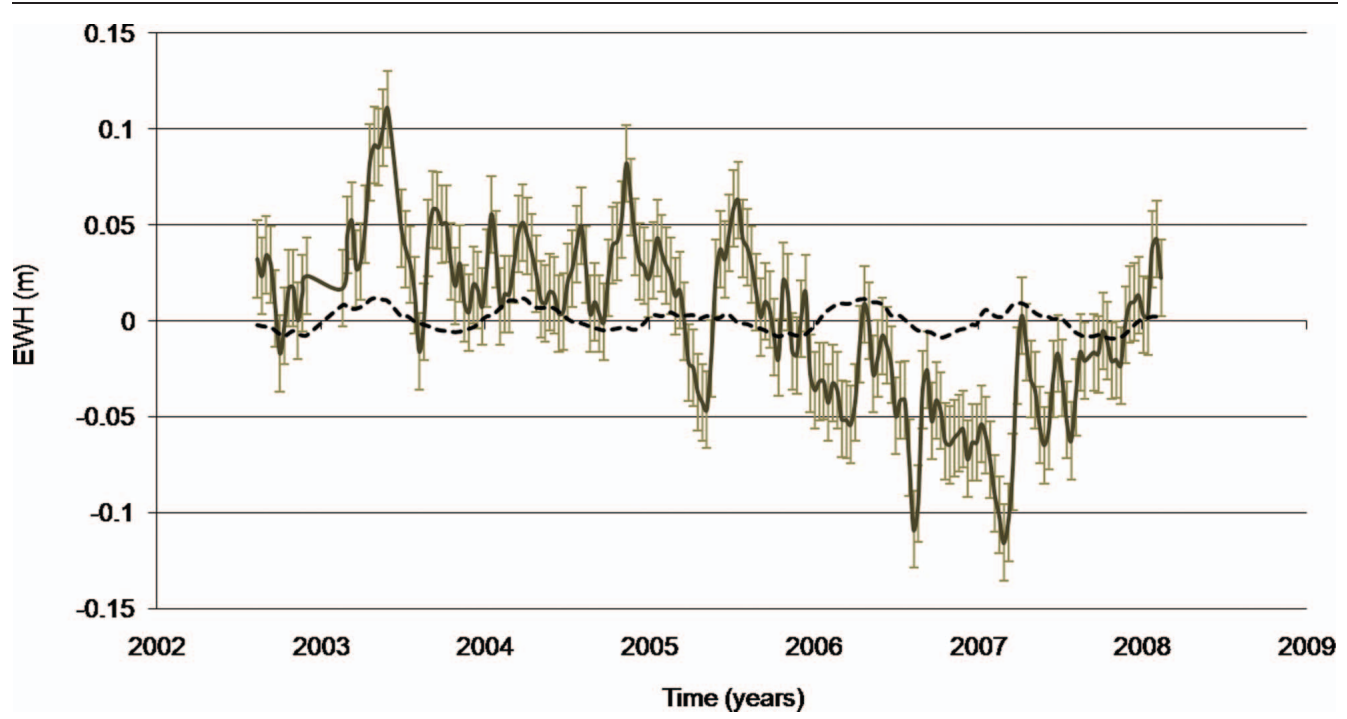

Figure 5 Murray-Darling Basin signal from GRGS products (black solid) with global averaged uncertainies (grey vertical bars) and the combined contamination in the Murray-Darling Basin (black dashed)

\section{CONCLUSIONS}

Simulations have shown that the combined contamination from near-field and far-field signals only generates a maximum of $\sim 10 \mathrm{~mm}$ spurious signal in basin-scale estimates of total water storage variation in the Murray-Darling Basin using GRACE products. This is well below the formal uncertainties of the estimates from the degree 50 spherical-harmonic fields of the Groupe de Recherche en Géodesie Spatiale. Thus, conventional techniques of scalar products of regional kernels and temporal gravity fields can be used with confidence to estimate hydrological processes in this region without the need to correct for leakage effects from external sources.

\section{ACKNOWLEDGEMENTS}

We thank the GRGS GRACE team for making their temporal fields freely available and journal reviewers Joseph Awange and Adam Smith for their constructive feedback.

\section{REFERENCES}

CARRĖRE L. \& LYARD F. 2003. Modeling the barotropic response of the global ocean to atmospheric wind and pressure forcingcomparison with observations. Geophysical Research Letters $\mathbf{3 0}$, 1275, doi:10.1029/2002GL016473.

CHAO B. F. \& GROSS R. S. 1987. Changes in the Earth's rotation and low-degree gravitational field induced by earthquakes. Geophysical Journal of the Royal Astronomical Society 91, 569-596.
DEWHA 2009. The Murray-Darling Basin, URL: < http://www. environment.gov.au/water/locations/murray-darling-basin/index. $\mathrm{html}>$

GRACE 2007. Gravity Recovery And Climate Experiment. URL $<$ http://www.csr.utexas.edu/grace $>$ or $<$ http://www.gfz-pots dam.de/pb1/op/grace >

Leblanc M. J., Tregoning P., Ramillien G., Tweed S. O. \& Fakes A 2009. Basin scale, integrated observations of the early 21st Century multi-year drought in southeast Australia. Water Resources Research 45, W04408, doi:10.1029/2008WR007333.

Lemoine J-M., BRUinsma S., LOYER S., Biancale R., MARTy J-C., Perosanz F. \& BALMino G. 2007. Temporal gravity field models inferred from GRACE data. Advances in Space Research 39, 16201629.

Llubes M., LEMOINE J-M. \& REMY F. 2007. Antarctica seasonal mass variations detected by GRACE. Earth and Planetary Science Letters 260, 127-136.

LYARD F., LEFEVRE F., LETELLIER T. \& FRANCIS O. 2006. Modelling the global ocean tides: modern insights from FES2004. Ocean Dynamics 56, 394-415.

OKI T. \& SuD Y. C. 1998. Design of Total Runoff Integrating Pathways (TRIP) - a global river channel network. Earth Interactions 2, $1-37$.

Ramillien G., Frappart F., Cazenave A. \& GÜntner A. 2005. Time variations of land water storage from an inversion of 2 years of GRACE geoids. Earth and Planetary Science Letters 235, 283-301.

Ramillien G., Lombard A., Cazenave A., Ivins E. R., Llubes M., REMY F. \& BIANCALE R. 2006. Interannual variations of the mass balance of the Antarctica and Greenland ice sheets from GRACE. Global and Planetary Change 53, 198-208.

RODELl M., HOUSER P. R., JAMBOR U., GOTTSCHALCK J., Mitchell K. Meng C-J., Arsenault K., Cosgrove B., Radakovich J., Bosilovich M., Entin J. K., WalkeR J. P., LOHMANN D. \& TOLL D. 2004. The Global Land Data Assimilation System. Bulletin of the American Meteorological Society 85, 381-394

SCHMidt R., SCHWintzer P., Flechtner F., REIGBer CH., GÚnter A. Döll P., Ramillien G., Cazenave A., Petrovic S., Jochmann H. \& WÜNSCH J. 2006. GRACE observations of changes in continental water storage. Global and Planetary Change 50, $112-126$ 
SEO K. W. \& WiLSON C. R. 2005. Simulated estimation of hydrological loads from GRACE. Journal of Geodesy 78, 442-456.

SWENSON S. \& WAHR J. 2002. Methods for inferring regional surfacemass anomalies from Gravity Recovery and Climate Experiment (GRACE) measurements of time-variable gravity. Journal of Geophysical Research 107(B9), 2193, doi:10.1029/2001JB000576.

SWENSON S. \& WAHR J. 2006. Post-processing removal of correlated errors in GRACE data. Geophysical Research Letters 33, doi:10. 1029/2005GL025285.

TAPley B. D., BettadpuR S., Ries J. C., Thompson P. F. \& Watkins M. W. 2004. GRACE measurements of mass variability in the Earth system. Science 305, 503-505.
VELICOGNA I. \& WAHR J. 2006. Measurements of time-variable gravity show mass loss in Antarctica. Science 311, 1754-1756.

WAHR J. M, JAYNE S. R. \& BRYAN F. O. 2002. A method of inferring changes in deep ocean currents from satellite measurements of time-variable gravity. Journal of Geophysical Research 107, doi:10.1029/2001JC001274.

WAHR J., MOLENAAR M. \& BRYAN F. 1998. Time variability of the Earth's gravity field: hydrological and oceanic effects and their possible detection using GRACE. Journal of Geophysical Research 103(B12), 30205-30229.

Received 12 October 2009; accepted 6 January 2010 